\title{
Correlation of Ankle-Brachial Index with Diabetic Retinopathy in Patients of Type 2 Diabetes
}

\author{
Abdullah Mazhar, Tayyaba Gul Malik, Aalia Ali, Hina Nadeem
}

Pak J Ophthalmol 2019, Vol. 35, No. 4

See end of article for

authors affiliations

Correspondence to:

Professor Tayyaba Gul Malik Department of Ophthalmology, Rashid Latif Medical College, Lahore.

Email: tayyabam@yahoo.com
Purpose: To find a relationship of diabetic retinopathy with ankle-brachial (ABI) in patients of type 2 diabetes.

Study Design: It was a cross-sectional observational study.

Place and Duration of Study: Arif Memorial Teaching hospital and Rashid Latif Medical College from January 2019 to June 2019.

Material and Methods: 120 patients were selected by purposive convenient sampling from outpatient department of Arif Memorial Teaching hospital. After clinical history, complete ocular examination was performed. Random blood glucose levels were measured using Glucometer. Ankle-brachial index was calculated by dividing the systolic pressure at ankle by the systolic blood pressure at arm. Statistical analysis was done using SPSS 25. Independent sample t test and chi square tests were used to find out the significance of the results.

Results: In this study of 120 diabetic patients, 80 (66.7\%) were female and 40 $(33.3 \%)$ were males. Mean Ankle Branchial Index (ABI) of Males was $0.96 \pm$ 0.11 and for females was $0.97 \pm 0.14$. Among 120 participants of this study, 73 $(60.83 \%)$ patients had no signs of diabetic retinopathy, $35(29.16 \%)$ patients had NPDR and $12(10 \%)$ patients had PDR. ABI was not associated with gender and duration of diabetes. However, there was negative and weak linear relationship between BSR and ABI $(r=-0.221)$. This correlation was higher in diabetics of less than 5 year duration $(r=-0.286)$ than in patients of more than 5 years duration of diabetes $(r=-0.129)$.

Conclusion: Our study indicates that $A B I$ is not significantly related with diabetic retinopathy. However, there is a weak linear relationship of $A B I$ with high blood sugar levels.

Key Words: Ankle brachial index, toe-brachial index, diabetic retinopathy.
$\mathrm{I}$ $\mathrm{n}$ late 1960s, Ankle-brachial index (ABI) was developed as a simple test to find out existence of peripheral artery disease especially the Lower extremity artery disease (LEAD). The American Diabetes Association has recommended screening for LEAD in all diabetic patients ${ }^{1}$. LEAD increases the risk of complications of diabetes including diabetic retinopathy, cardiovascular episodes and even death in severe cases $^{2,3}$. In normal persons, lower limb systolic pressure at ankle is 10 to $15 \mathrm{~mm} \mathrm{Hg}$ greater than pressure at arm. This is responsible for ABI of about 1.1 to 1.3. A range between 0.9 to 1.0 is suspicious, less than 0.9 is dangerous and indicative of peripheral artery disease. However, more than 1.4 is also abnormal and it shows calcification and stiffening of arteries (poorly compressible arteries).

As micro-angiopathy and macro-angiopathy, 
which are responsible for peripheral artery disease, are reflected in retina as diabetic retinopathy, we have tried to find out a relation between $\mathrm{ABI}$ and diabetic retinopathy in this research.

The purpose of this study was to find a relationship of diabetic retinopathy with anklebrachial (ABI) in patients of type 2 diabetes.

\section{MATERIAL AND METHODS}

It was a cross-sectional observational study carried out from January 2019 to June 2019. Institutional ethical review board approved the study. Sample size was calculated by WHO software 2.0. 120 patients were selected by purposive convenient sampling from outpatient department of Arif Memorial Teaching hospital.

All Patients with type 2 diabetes between 25 and 80 years of age of both genders were included in the study. Exclusion criteria were patients with systemic diseases other than diabetes, type 1 diabetic patients, smokers, patients who had undergone laser therapy or intravitreal anti-VEGF injections for diabetic

Table 2: Association of ABI with gender, duration of diabetes and diabetic retinopathy.

\begin{tabular}{|lllll|}
\hline \multirow{2}{*}{ Variable } & & \multicolumn{2}{l|}{ Ankle Branchial Index } & \multirow{2}{*}{ P-value } \\
& & Normal (1-1.4) & Below 1 & \multirow{2}{*}{ Gender } \\
\multirow{2}{*}{ Duration of } & Male & $39(49.4 \%)$ & $40(50.6 \%)$ & \multirow{2}{*}{0.333} \\
Diabetes & $<5$ years & $25(40.0 \%)$ & $24(60.0 \%)$ & \\
& $>5$ years & $30(48.4 \%)$ & $32(56.1 \%)$ & \multirow{2}{*}{0.621} \\
Ophthalmoscopy & $32(51.6 \%)$ & \\
& NAD & $37(51.4 \%)$ & $35(48.6 \%)$ & \multirow{2}{*}{0.082} \\
& NPDR & $16(45.7 \%)$ & $19(54.3 \%)$ & \\
& PDR & $2(16.7 \%)$ & $10(83.3 \%)$ & \\
\hline
\end{tabular}

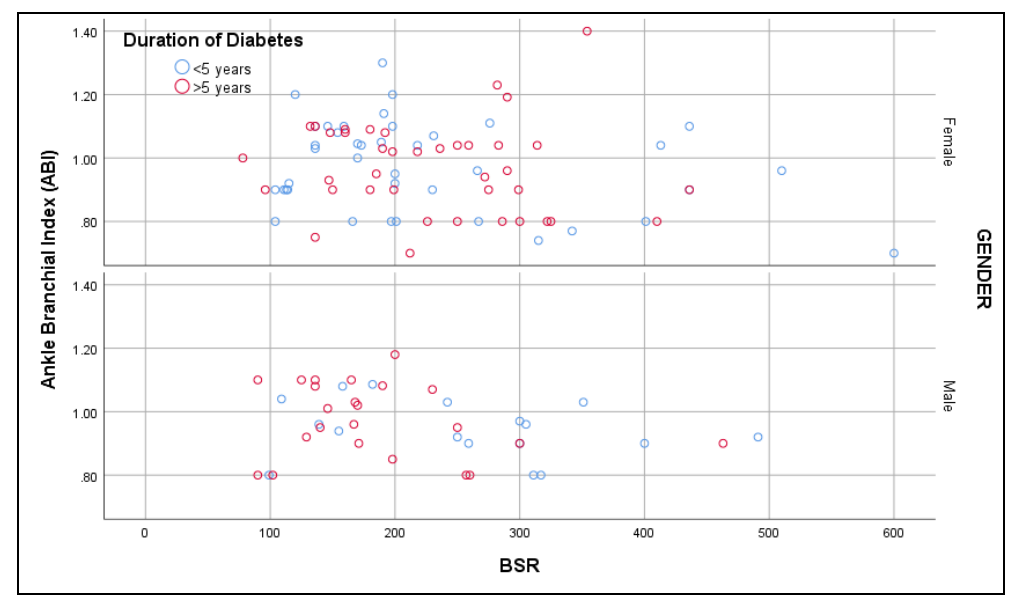

Graph 1: Relation of ABI with gender, BSR and duration of diabetes. retinopathy and patients with vitreo-retinal diseases other than diabetic retinopathy.

Table 1: Association of ABI with BSR and duration of diabetes.

\begin{tabular}{lccc}
\hline \multirow{2}{*}{ ABI } & \multicolumn{2}{c}{ BSR and duration of Diabetes } & \multirow{2}{*}{ <-value } \\
& $<5$ years & $>\mathbf{5}$ years & \\
\hline Normal & $203.28 \pm 84.42$ & $193.87 \pm 66.42$ & 0.645 \\
Below & $259.94 \pm 131.21$ & $235.09 \pm 95.37$ & 0.390 \\
p-value & 0.066 & 0.054 & \\
\hline
\end{tabular}

After clinical history, examination was performed. Random blood glucose levels were measured using Glucometer. We checked visual acuity for distance and near. Pupillary reactions were checked. Slit lamp examination was performed to inspect any anterior segment abnormality. Goldman tonometry was done to check intra ocular pressures. Fundus examination was performed using $90 \mathrm{D}$ lens at slit lamp and with indirect ophthalmoscope. Retinal findings were categorized into, NAD (no abnormality detected), NPDR (non-proliferative diabetic retinopathy) and PDR (proliferative diabetic retinopathy).

We determined Ankle-brachial index by checking the systolic blood pressure in supine position with the help of mercury sphygmomanometer. Blood pressure was recorded in both arms in supine position after 5 minutes of resting. Mean of the two pressures was taken as brachial systolic pressure. The cuff was inflated $20 \mathrm{~mm} \mathrm{Hg}$ higher than the arm systolic blood pressures while ankle pressures were measured at dorsalis pedis artery. Anklebrachial index was calculated by dividing the systolic pressure at ankle by the systolic blood pressure at arm.

All data was collected using a selfdesigned proforma and compiled in excel file. Statistical analysis was done using SPSS 25. Independent sample $t$ test and chi square tests were used to find out the significance of the results.

\section{RESULTS}

In this study of 120 diabetic patients, 80 $(66.7 \%)$ were female and $40(33.3 \%)$ were males. Mean age of the females was 50.94 \pm 12.74 years and mean age of males was $51.98 \pm 10.73$ years. Mean BSR of Males 
was $216.28 \pm 98.94$ and in females was $227.19 \pm 102.61$. MeanAnkle Branchial Index (ABI) of Males was $0.96 \pm$ 0.11 and for females was $0.97 \pm 0.14$ (table 2).

Among 120 participants of this study, 58 patients had diabetes for less than 5 years and 62 were suffering from this disease for more than 5 years. Seventy three $(60.83 \%)$ patients had no signs of diabetic retinopathy, 35 (29.16\%) patients had NPDR and $12(10 \%)$ patients had PDR (table 2). ABI was not associated with gender and duration of diabetes. See table 1 .

Patients who had ABI in normal range had mean BSR 198.15 \pm 74.56. Patients who had low ABI had BSR of $247.52 \pm 114.47$. This difference was statistically significant ( $p$-value 0.007). There was negative and weak linear relationship between BSR and ABI $(\mathrm{r}=-0.221)$. This correlation was higher in diabetics of less than 5 year duration $(r=-0.286)$ than in patients of more than 5 years duration of diabetes $(r=-0.129)$.

\section{DISCUSSION}

Lower extremity artery disease, also known as peripheral artery disease (PAD) is a common complication of diabetes and it increases with increase in the duration of diabetes. Studies have shown that diabetic retinopathy is an independent risk factor for PAD $^{4}$. ABI has a sensitivity of $90 \%$ and specificity of $95 \%$ for angiographically proved PAD ${ }^{5}$. Diabetic patients are prone to PAD and hence abnormal and borderline $A B I$ is a very useful, non-invasive test to detect $\mathrm{PAD}^{6}$. ABI values of 1 to 1.3 are considered normal, less than 1 are abnormal but the 2011 American College of Cardiology Foundation (ACCF) and American Heart Association (AHA) guidelines for the management of PAD have recommended $\mathrm{ABI}$ values of $0.90-0.99$ as 'borderline' ${ }^{7}$. In our study, we took 0.9 as abnormal rather than borderline.

Studies have shown that women were more likely to have borderline ABI (11.6\%) than men $(8.0 \%)^{8}$. Similarly, in the National Health and Nutrition Examination Survey NHANES (1999-2002) and the Multi-Ethnic Study of Atherosclerosis (MESA), the prevalence of borderline ABI nearly doubled in women $(11.7 \%$ and $10.6 \%)$ than men $(6.0 \% \text { and } 4.3 \%)^{9}$. This was not the case in our study and ABI was not significantly higher in women as compared to men $(\mathrm{p}=.333)$.

Low ABI is also associated with increased risk of mortality ${ }^{10}$. Studies have shown that Ankle-brachial index is very effective and cost effective tool for diagnosis of $\mathrm{PAD}^{11}$. However, $\mathrm{ABI}$ values have shown variable results in diabetic patients as compared to normal population ${ }^{12}$.

Different studies have shown varying results of association of diabetic retinopathy with ABI. One of the reasons for studying $\mathrm{ABI}$ in our diabetic population was that this relation is not yet studied in our population and to the best of our knowledge; this is the first research being reported from Pakistan.

Our data revealed that, there was no statistically significant relation of diabetic retinopathy with abnormal or low ABI. Contrary to this, Papanas et al had shown low ABI in type 2 diabetic patients with diabetic retinopathy ${ }^{13}$. Similarly, Emerson et al. described a direct relation of severity of diabetic retinopathy and microalbuminuria with abnormal ABI scores. This indicated that patients with abnormally low ABI have not only the kidneys at stake but also their vision ${ }^{14}$. Other studies have shown similar results indicating $\mathrm{ABI}$ as a marker of not only PAD but also diabetic retinopathy $15,16,17,18$. According to Joint Asia Diabetes Evaluation Program, 12,777 patients with type 2 diabetes had borderline ABI, which was associated with increased prevalence of microvascular complications. ABI was found to be an independent risk factor for diabetic retinopathy in a Chinese study ${ }^{19}$. (Odds ratios: 1.19 (95\% confidence interval: 1.04-1.37)). They also proposed a higher cut off value $<1.0$ to early prevent onset of diabetic complications including Diabetic retinopathy (DR). They also described association of low ABI with duration of diabetes, which is consistent to our study.

Similar results were reported from Germany ${ }^{20}$. Zander et al supported an increased prevalence of diabetic retinopathy and neuropathy in patients with abnormal ABI values. Overall, in their study, patients with diabetic retinopathy had higher proportion of low ABI than those without DR. (53 out of 138 vs. 59 out of 337).

Another study from china with Multivariate forward logistic regression analysis showed positive relation of PDR with abnormal ABI as compared to non-DR. However, NPDR was not significantly related with abnormal ABI when compared with normal population $^{21}$.

There are conflicting data as far as ABI and DR are concerned. There were other reports, which were similar to our results showing no relationship of $\mathrm{ABI}$ to presence or absence of retinopathy in diabetic individuals. Yun et al related their negative findings 
regarding $\mathrm{ABI}$ and $\mathrm{DR}$ with other conditions for example sample size, age and characteristics of study population ${ }^{16}$. Similarly, a study from Israel showed that type 2 diabetes was associated with higher BMI, larger waist circumference but ABI was normal in all patients with or without $\mathrm{DR}^{22}$. This variability of results was explained by some researchers in terms of arterial stiffness. When ABI is measured in patients with arterial stiffness, which is also associated with diabetes, ABI values appear higher due to lesser vascular compressibility. Hence, ABI values in diabetic patients show lower prevalence in some studies. For the same reason some epidemiological researchers have shown that $\mathrm{ABI}<0.9$ as well as $>1.4$ is indicative of PAD 23,24 .

Strength of this research is that this study was conducted to find a relation of ABI with diabetic retinopathy in Pakistani population. Our limitation was that, as normal ABI in our study could have been due to arterial calcification, we can further expand our research using toe-brachial index, which according to some recent data, is found to be of superior diagnostic value as compared to the $\mathrm{ABI}{ }^{25}$.

\section{CONCLUSION}

Our study indicates that ABI is not significantly related with diabetic retinopathy. However, there is a weak relationship of decreased ABI with high blood glucose levels.

\section{DECLARATIONS}

Authors declare no conflict of interest in this study. There was no funding source. The institutional review board approved the research.

\section{REFERENCES}

1. American Diabetes Association. Standards of medical care in diabetes - 2013. Diabetes Care, 2013; 36: 11-66.

2. Criqui $\mathbf{M H}$, Aboyans V. Epidemiology of peripheral artery disease. Circ Res. 2015; 116 (9I): 1509-26.

3. Selvin E, Erlinger TP. Prevalence of and risk factors for peripheral arterial disease in the United States: results from the National Health and Nutrition Examination Survey, 1999-2000. Circulation. 2004; 110 (6I): 738-43.

4. Nativel M, Potier L, Alexandre L, Baillet-Blanco L, Ducasse E, Velho G, et al. Lower extremity arterial disease in patients with diabetes: a contemporary narrative review Cardiovasc Diabetol. 2018; 17: 138.

5. Criqui MH. Systemic atherosclerosis risk and the mandate for intervention in atherosclerotic peripheral arterial disease. Am J Cardiol. 2001; 88: 43J-47J.
6. Natsuaki C, Inoguchi T, Maeda Y, Yamada T, Sasaki S, Sonoda $\mathbf{N}$, et al. Association of borderline anklebrachial index with mortality and the incidence of peripheral artery disease in diabetic patients. Atherosclerosis, 2014; 234: 360-365.

7. American College of Cardiology Foundation, American Heart Association Task Force, Society for Cardiovascular Angiography and Interventions, et al. 2011 ACCF/AHA focused update of the guideline for the management of patients with peripheral artery disease (updating the 2005 guideline). Vasc Med. 2011; 16: 452-476.

8. McDermott MM, Liu K, Criqui MH, Ruth K, Goff D, Saad MF, et al. Ankle-brachial index and subclinical cardiac and carotid disease: the multiethnic study of atherosclerosis. Am J Epidemiol. 2005; 162: 33-41.

9. Menke A, Muntner P, Wildman RP, Dreisbach AW, Raggi P. Relation of borderline peripheral arterial disease to cardiovascular disease risk. Am J Cardiol. 2006; 98: 1226-1230.

10. Khan T, Farooqi F, Niazi K. Critical review of the ankle brachial index. Curr Cardiol Rev. 2008; 4: 101-106.

11. Weiss NS, McClelland R, Criqui $\mathrm{MH}$, Wassel $\mathrm{CL}$, Kronmal R. Incidence and predictors of clinical peripheral artery disease in asymptomatic persons with a low ankle-brachial index. J Med Screen, 2018; 25 (4): 218-222.

12. Guirguis-Blake JM, Evans CV, Redmond N, Lin JS Screening for peripheral artery disease using the anklebrachial index: updated evidence report and systematic review for the US preventive services task force. JAMA. 2018; 320 (2I): 184-96.

13. Papanas N, Symeonidis G, Mavridis G, Georgiadis GS, Papas TT, Lazarides MK, et al. Ankle-brachial index: a surrogate marker of microvascular complications in type 2 diabetes mellitus? Int Angiol. 2007; 26 (3): 253-257 17622207.

14. Molina EJB, Yutangco RA, Cruz-Anacleto MAS, Castillo JDD, Aguinod-Cheng PJ. Relationship of Diabetic Retinopathy with Ankle Brachial Index and Microalbuminuria in Type 2 Diabetics Philipp J Ophthalmol. 2014; 39: 12-15.

15. Kawasaki R, Cheung N, Islam A, Klein R, Klein BEK, Cotch MF et al. Is diabetic retinopathy related to subclinical cardiovascular disease? Ophthalmology, 2011; 118: 860-865.

16. Yun YW, Shin MH, Lee YH, Rhee JA, Choi JS. Arterial stiffness is associated with diabetic retinopathy in Korean type 2 diabetic patients. J Prev Med Public Health, 2011; 44: 260-266.

17. Tryniszewski W, Gadzicki M, Maziarz Z, Kusmierczyk J, Gos R, Rysz J, et al. Progression of diabetic retinopathy correlated with muscle perfusion disturbances of the lower limbs, with clinically important diagnostic recommendations. Arch Med Sci. 2010; 6: 904-911.

18. Rani P, Raman R, Gupta A, Pal SS, Kulothungan V, Sharma T. Albuminuria and diabetic retinopathy in 
type 2 diabetes mellitus. Sankara Nethralaya Diabetic Retinopathy Epidemiology and Molecular Genetic Study (SN-DREAMS, report 12). Diabetol Metab Syndr. 2011; 3: 9.

19. Yan BP, Zhang Y, Kong AP, Luk AO, Ozaki R, Yeung $\mathbf{R}$, et al. Borderline ankle-brachial index is associated with increased prevalence of micro- and macrovascular complications in type 2 diabetes: A cross-sectional analysis of 12,772 patients from the Joint Asia Diabetes Evaluation Program. Diabetes Vasc Dis Re. 2015; 12 (5): 334-341.

20. Zander E, Heinke P, Reindel J, Kohnert KD, Kairies U, Braun J, et al. Peripheral arterial disease in diabetes mellitus type 1 and type 2: are there different risk factors? Vasa. 2002; 31: 249e54.

21. Chen SC, Hsiao PJ, Huang JC, Lin KD, Hsu WH, Lee YL, et al. Abnormally Low or High Ankle-Brachial Index Is Associated with Proliferative Diabetic Retinopathy in Type 2 Diabetic Mellitus Patients. PLoS

\section{Author's Affiliation}

Abdullah Mazhar

Department of Ophthalmology, Rashid Latif Medical College, Lahore

Tayyaba Gul Malik

Department of Ophthalmology, Rashid Latif Medical College, Lahore

Aalia Ali

Department of Ophthalmology, Arif Memorial Teaching Hospital, Lahore

Hina Nadeem

Department of Ophthalmology, Arif Memorial Teaching Hospital, Lahore
ONE. 2015; 10 (7): e0134718.

22. Blum A, Socea D. Clinical Characteristics of Diabetic Patients with Diabetic Retinopathy. J. Nutr. Ther. 2013; 2 (1): 46-52.

23. Aboyans V, Ho E, Denenberg JO, Ho LA, Natarajan L, Criqui MH. The association between elevated ankle systolic pressures and peripheral occlusive arterial disease in diabetic and nondiabetic subjects. J Vasc Surg. 2008; 48 (5): 1197-1203 18692981.

24. Papanas N, Symeonidis G, Mavridis G, Georgiadis GS, Papas TT, Lazarides MK, et al. Ankle-brachial index: a surrogate marker of microvascular complications in type 2 diabetes mellitus? Int Angiol. 2007; 26 (3): 253-257 17622207.

25. Tehan PE, Barwick AL, Sebastian M, Helaine V. Diagnostic accuracy of resting systolic toe pressure for diagnosis of peripheral arterial disease in people with and without diabetes: a cross-sectional retrospective case-control study. J Foot Ankle Res. 2017; 10: 58.

\section{Author's Contribution}

Abdullah Mazhar

Data acquisition and analysis, literature research and final review.

Tayyaba Gul Malik

Research planning, data acquisition and analysis, literature research, manuscript writing and final review.

Aalia Ali

Data acquisition and analysis, literature research and final review.

Hina Nadeem

Data acquisition, Data analysis, final manuscript review. 